MITSUBISHI ELECTRIC RESEARCH LABORATORIES

http://www.merl.com

\title{
A Review of Recent Development on Digital Transmitters with Integrated GaN Switch-Mode Amplifiers
}

\author{
Ma, R. \\ TR2015-115 August 2015
}

\begin{abstract}
GaN integrated switch-mode power amplifier with high output power, fast and efficient switching characteristic has been considered as a very suitable technology for implementing advanced digital radio transmitter. It is featured of energyefficient and re-configurable operation. This paper reviews the recently reported works in this promising research topic. Key technical challenges on the device technology, modeling, and circuit designs are summarized. Future development trend is discussed.
\end{abstract}

2015 IEEE International Symposium on Radio-Frequency Integration Technology (RFIT2015)

This work may not be copied or reproduced in whole or in part for any commercial purpose. Permission to copy in whole or in part without payment of fee is granted for nonprofit educational and research purposes provided that all such whole or partial copies include the following: a notice that such copying is by permission of Mitsubishi Electric Research Laboratories, Inc.; an acknowledgment of the authors and individual contributions to the work; and all applicable portions of the copyright notice. Copying, reproduction, or republishing for any other purpose shall require a license with payment of fee to Mitsubishi Electric Research Laboratories, Inc. All rights reserved. 



\title{
A Review of Recent Development on Digital Transmitters with Integrated GaN Switch-Mode Amplifiers
}

\author{
Rui Ma, Senior Member, IEEE \\ Mitsubishi Electric Research Laboratories (MERL) \\ 201 Broadway, Cambridge, MA, USA, 02139 \\ E-mail: rma@merl.com
}

\begin{abstract}
GaN integrated switch-mode power amplifier with high output power, fast and efficient switching characteristic has been considered as a very suitable technology for implementing advanced digital radio transmitter. It is featured of energyefficient and re-configurable operation. This paper reviews the recently reported works in this promising research topic. Key technical challenges on the device technology, modeling, and circuit designs are summarized. Future development trend is discussed.
\end{abstract}

Keywords-GaN; MMIC; Switch-Mode; Power Amplifier;

\section{INTRODUCTION}

The term "software defined radio" (SDR) was coined in 1990s to attempt to place most of the complex signal processing involved in transceivers into the digital domain. Benefiting from Moore's law, tremendous progress has been made to improve the capability of signal processing units in the recent decades. As a result, this gradually enables digital transmitter for SDR for cellular applications at $\mathrm{GHz}$ range, which was feasible only at audio frequency [1-3].

A diagram of typical all-digital transmitter is represented in Fig. 1. Majority of signal processing is performed in the digital domain, using either digital signal processor (DSP) or ASIC (application-specific integrated circuit). A train of high speed digital-RF signals (several Gbps in single or multi-bits) with rectangular wave shape, which is generated directly by power encoder block, is fed to a high efficiency switch-mode power amplifier (PA), e.g. class-D/-S. Its theoretical efficiency is $100 \%$. At the end, a band-pass filter is normally needed after PA to reconstruct analog waveforms for antenna radiation.

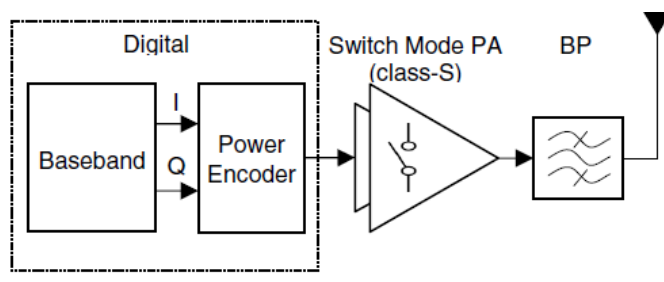

Fig. 1. Tyical all-digital transmitter architecture.

In principle, frequency up-conversion is implemented digitally with digital LO and mixing functions. Delta sigma modulation (DSM) and pulse width modulation (PWM) are the common methods for quantization to generate the digital-RF bits [4]. Digital-to-analog conversion (DAC) is happening at the output of the power amplifier. Re-configurable operation for different RF frequencies and signal standards can be done by algorithm update within power encoder, relying on minimum external hardware changes, e.g. only tunable filter part. For example, to transmit concurrent multi-band RF signals in inter-band carrier aggregation (CA) in LTEAdvanced with traditional transmitter using wideband or multiband PA is less-flexible and inefficient [2]. Instead, it can be handled by digital transmitter using switch-mode PA with promising performance, as demonstrated in [4-5].

For digital transmitter, several publications have discussed the critical roles of power encoding block [4-7]. This paper will focus on summarizing the technical challenges and recent development of switch-mode PA, in particular using $\mathrm{GaN}$ (gallium nitride) based MIC (microwave integrated circuit) technology. It is well-known that $\mathrm{GaN}$ is a promising technology for high power and high frequency applications, which manifest itself very suitable for designing switch-mode PA [7-9]. However, there are several unique challenges to be considered including GaN device technology, modeling and PA circuit design. These will be reviewed in the next section. Finally, future development trend of digital transmitter will be provided at section III.

\section{KEY CHALLENGES}

\section{A. GaN Technology}

To enhance the efficiency of whole digital transmitter, it is essential to reduce various kinds of losses in the active GaN switch devices, as shown in Fig. 2. It includes both static losses contributed mainly by device on-resistance $\mathrm{R}_{\mathrm{on}}$ and switching losses due to parasitic capacitances $\left(\sim \mathrm{C} \cdot \mathrm{f}_{\mathrm{sw}}{ }^{2}\right)$ [10-13]. The power encoded waveform of a broadband modulated signals is non-periodic and often several times (2 5) faster than the fundamental RF carrier frequencies, due to over-sampling in power encoding procedure. Consequently, it causes the increases of effective $R_{\text {on }}$, which is bigger than $R_{\text {on }}$ in static $D C$ status (approximately increase $>30 \%$ ) [13]. It is also preferred to reduce the turn-on/turn-off transitions through advanced power encoding algorithm [10]. Minimized $\mathrm{R}_{\mathrm{on}}$ has also positive influence on the parasitic capacitance. Reduced parasitic capacitance $\left(\mathrm{C}_{\mathrm{gs}}, \mathrm{C}_{\mathrm{gd}}\right.$, and $\left.\mathrm{C}_{\mathrm{ds}}\right)$ can contribute to a 
faster and efficient switching (higher slew-rate of turn $\mathrm{ON}$ and OFF with minimized overlap of current and voltage waveforms).

Another issue is that the nature of input power encoded input signal is ultra-wideband starting from almost DC to several times of RF frequency (10 20 times). It thus requires a high device cut-off frequency $f_{T}$. Currently, devices with gate length of $0.15 \mu \mathrm{m} \sim 0.5 \mu \mathrm{m}$ have been reported [8-13]. The reduced gate length offers usually higher efficiency and higher trans-conductance but has negative influence on the device breakdown voltage.

Recently published literatures [8-13] have demonstrated very promising progress for digital transmitter with GaN. For example, FBH group reported in [8] around $90 \%$ at $1.8 \mathrm{Gbps}$ for an output power of $17 \mathrm{~W}$ for typical BPDS (bandpass delta sigma modulation) or PRBS (pseudorandom binary sequence) signal with gate width of $2 \times 8 \times 250 \mu \mathrm{m}$. This efficiency refers to the power switch alone, which is the ratio of the broadband output powers for a $50 \Omega$ to the consumed DC power.

The GaN technology reported from IAF in [9] is a $0.25 \mu \mathrm{m}$ gate length T-gate with $22 \mathrm{~nm} \mathrm{Al}_{0.22} \mathrm{Ga}_{0.78} \mathrm{~N}$ barrier with a thin $\mathrm{GaN}$ cap layer on a 3-inch semi-insulating $\mathrm{SiC}$ substrate, with a threshold voltage of $-2.7 \mathrm{~V}$. Its key parameters are listed in Table I.

TABLE I. GAN DEVICE PERFORMANCE

\begin{tabular}{|c|c|}
\hline $\mathrm{I}_{\mathrm{D}, \max }$ & $1050 \mathrm{~mA} / \mathrm{mm}$ \\
\hline $\mathrm{g}_{\mathrm{m}, \max }$ & $330 \mathrm{mS} / \mathrm{mm}$ \\
\hline $\mathrm{R}_{\mathrm{s}}$ & $0.7 \Omega \cdot \mathrm{mm}$ \\
\hline $\mathrm{R}_{\mathrm{on}}$ & $3 \Omega \cdot \mathrm{mm}$ \\
\hline $\mathrm{BV}_{\mathrm{GS}}\left(\mathrm{T}=150^{\circ} \mathrm{C}\right)$ & $>60 \mathrm{~V}$ \\
\hline $\mathrm{BV}_{\mathrm{GD}}\left(\mathrm{T}=150^{\circ} \mathrm{C}\right)$ & $>120 \mathrm{~V}$ \\
\hline $\mathrm{f}_{\mathrm{t}}$ & $32 \mathrm{GHz}$ \\
\hline $\mathrm{f}_{\max }$ & $42 \mathrm{GHz}$ \\
\hline
\end{tabular}

Difference in de-trapping and trapping time constant could affect the turn-on and turn-off wave forms causing distortion, thus needs to be controlled. Reducing threshold voltage can mitigate the challenge of voltage swing requirement of the driver circuits.

\section{B. Device Modeling}

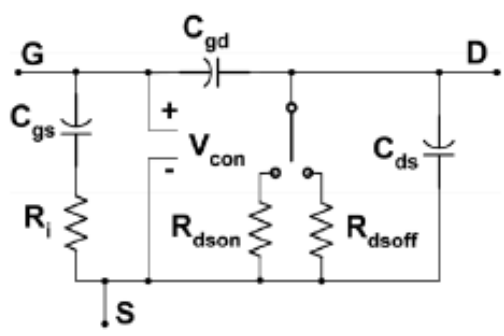

Fig. 2. Simplified device model for switch-mode PA operation [14].

The operation area (load-line) of switch-mode power amplifier is significantly different from the traditional linear power amplifier such as class-AB or Doherty PA [14-15]. Therefore, specially developed device model to represent the two main statuses (ON and OFF) is preferred. Fig. 2 shows the simplified device model for switch-mode applications. It is realized that accurately model the parasitic capacitance are critical for switch-mode operation. Time-domain and frequency domain verification should be done. Convergence is less problematic once dedicated simplified model is chosen, compared with the very complicated comprehensive device models.

\section{PA Circuit Design}

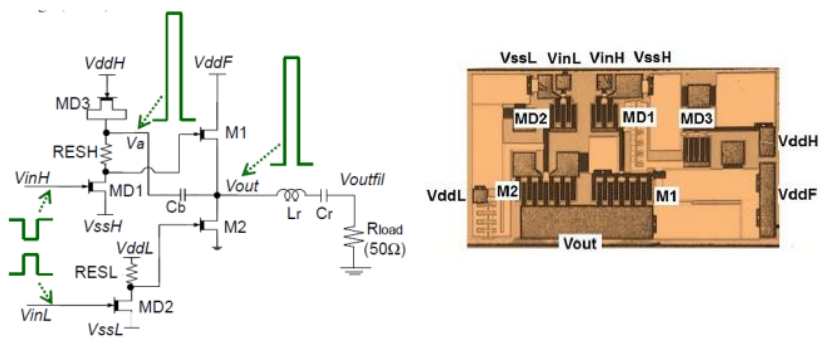

Fig. 3. Schemeatic and fabricated chip of GaN voltage-mode bootstrap strcutre [17].

Broadly speaking, there are two classes of switch-mode operation, namely voltage and current mode, depending on which waveform is rectangular. They both have pros and cons, as described in $[12,16]$. The output network of voltage-mode is single-ended, instead of balanced (current-mode relying on extra balun circuit), as shown in Fig. 3. However, it is notorious challenging to drive the upper final stage $\mathrm{GaN}$ switch in the voltage-mode operation. This is because its source is almost changing from $0 \mathrm{~V}$ to the supply voltage $(>20 \mathrm{~V})$, making its driver output voltage swing very challenging.

Therefore, significant efforts have been made for the innovative design of driver stages including the bootstrap reported by [17-18], as shown in Fig. 3. This remains to be a very demanding design task for high power $(>10 \mathrm{~W})$ and high frequency (>1 GHz RF frequency). The recent work [19] has proposed and developed the multi-stage structure to enhance the driver capability for upper switch with promising efficiency, as shown in Fig. 4.

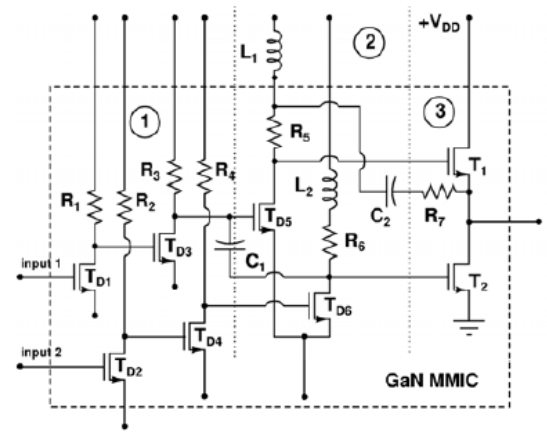

Fig. 4. Schemeatic of digital GaN voltage-mode PA MMIC [19]. 
Advanced multi-level (3/5-level) switch-mode PA topologies such as $\mathrm{H}$-bridge or extended $\mathrm{H}$-bridge is required to comply with the multi-level power encoded signal (higher coding efficiency). So far, H-bridge is the main demonstrated topology for GaN class-S PA for single-band and dual-band transmission at in the sub GHz cellular bands $[4,7,19]$.

Further innovation on both circuit design and power coding algorithm is need to boost the system performance for more challenging radio transmission.

\section{SUMMARY AND OUTLOOK}

This paper briefly reviews the advantages and challenges of designing switch-mode $\mathrm{GaN}$ power amplifier integrated circuit for digital transmitter. Optimized device technologies for faster, more efficient, and broadband switching characteristics, specially developed transistor models, and amplifier circuits topologies were discussed. It is envisioned that in the future, all-digital transmitter will be more suitable for ever-increasing challenges in the multi-standard and multi-frequency band radios owing to its true flexibilities and efficiency. With the development of advanced power encoding algorithm, digital signal processors, enhancement-mode of GaN HEMT, combining with enhanced driver circuitry, which can be realized in silicon CMOS [20] technology or SiGe technology [21]. Innovation on the reconstruction filters [22] is also necessary to improve the whole system performance. Linearization techniques such as digital pre-distortion (DPD) is necessary to minimize the distortion, which needs to be specially developed for class-S operation, to meet both the inband (e.g. EVM) and out-of-band (ACPR) requirement. In the future, monolithic and/or heterogonous integrations techniques maximizing the technologies strength with the highest performance are the development trend in the microwave industry, which could be applied also for the digital transmitter applications [23].

\section{ACKNOWLEDGMENT}

The author would like to appreciate all the valuable technical discussions and great teamwork with all interns Q. Zhu, S. Chung, and colleagues K. Teo from MERL as well as K. Mukai, S. Shinjo, H. Nakamizo, and K. Yamanaka from Mitsubishi Electric Corporation (MELCO) in Japan.

\section{REFERENCES}

[1] P. M. Asbeck, L. E. Larson, and I. G. Galton, "Synergistic Design of DSP and Power Amplifiers for Wireless Communications," IEEE Trans. MTT, vol. 49, no. 11, pp. 2163-2169, Nov. 2001.

[2] F. Ghannouchi, "Power Amplifier and Transmitter Architectures for Software Defined Radio Systems," IEEE Circuis and System Magazine, vol. 10, no. 4, pp. 56-63, Nov. 2010.

[3] P. A. J. Nuyts, P. Reynaert, and W. Dehaene, "A Fully Digital PWMbased 1 to $3 \mathrm{GHz}$ Multistandard Transmitter in 40-nm CMOS," IEEE MTT-S RFIC Digest, pp. 419-422, June 2013.

[4] S. Chung, R. Ma, S. Shinjo, H. Nakamizo, K. Parsons, and K. H. Teo, “ Concurrent Multiband Digital Outphasing Transmitter Architectures Using Multidimensional Power Coding," IEEE Trans. MTT, vol. 63, no. 2, pp. 598 - 613, Feb. 2015.

[5] A. Wentzel, S. Chevtchenko, P. Kurpas, and W. Heinrich, "A DualBand Voltage-Mode Class-D PA for 0.8/1.8 GHz Applications," IEEE
MTT-S International Microwave Sysmposium Digest, pp. 1-4, June 2013.

[6] Q. Zhu, R. Ma, C. Duan, and K. Teo, "A 5-Level Discrete-Time Power Encoder with Measured Coding Efficiency of $70 \%$ fo $20-\mathrm{MHz}$ LTE Digital Transmitter," IEEE MTT-S International Microwave Symposium Digitest, pp. 1-3, June 2014.

[7] A. Wentzel, C. Meliani, and W. Heinrich, "RF Class-S Power Amplifiers: State-of-Art Results and Potential," IEEE MTT-S International Microwave Symposium Digitest, pp. 812-815, May 2010.

[8] C. Meliani, J. Flucke, A. Wentzel, J. Wuerfl, W. Heinrich, and G. Traenkle, "Switch-Mode Amplifier ICs with over 90\% Efficeincy for Class-S Pas using GaAs-HBTs and GaN HEMTs," IEEE MTT-S International Microwave Symposium Digest, pp. 751-754, June 2008.

[9] S. Maroldt, C. Haupt, R. Kiefer, W. Bronner, S. Mueller, W. Benz, R. Quay, and O. Ambacher, "High Efficiency Digital GaN MMIC Power Amplifiers for Future Switch-Mode Based Mobile Communications Systems," IEEE CSICS Digiest, pp. 1-4, Oct. 2009.

[10] A. Braeckle, S. Heck, M. Berroth, and I. Dettmann, "Efficiency of Current-Mode Class-D Amplifiers with Delta-Sigma Modulated Drive Signals," German Microwave Conference Digest, pp. 1-4. March 2009.

[11] A. Pereira, A. Parker, M. Heimlich, N. West, and L. Dunleavy, " Characterization of GaN HEMTs for Integrated Supply Modulator," IEEE Power Amplifiers for Wireless and Radio Applications (PAWR) Digest, pp. 64-66, Jan. 2014.

[12] J. Park, J. Yook, B. Park, N. Jeon, K. Seo, D. Kim W. Lee, and C. Yoo, "Hybrid Current-Mode Class-S Power Amplifier With GaN Schottkey Diode using Chip-On-Board Technique for $955 \mathrm{MHz}$ LTE Signal," IEEE Trans. MTT, vol. 61, no. 12, pp. 4168-4178, Nov. 2013.

[13] S. Maroldt, "Gallium Nitride Based Transistors for High Efficiency Microwave Switch-Mode Amplifiers," Ph.D. Dissertation, University of Freiburg in Breisgau, Germany, June 2010.

[14] A. Wentzel, F. Schnieder, C. Meliani, and W. Heinrich, "A Simplified switch-based GaN HEMT Model for RF Switch-Mode Amplifiers," IEEE EuMIC Digest, pp. 28-29, Sept. 2009.

[15] M. Paynter, S. Bensmida, K. A. Morris, J. P. Mc Geeehan, et al. "Sensitivity Analysis of GaN Power Amplifier Model Paramters for Switching-Mode Operation," IEEE EuMIC Digest, pp. 76-79, Oct. 2012.

[16] A. Wentzel, C. Meliani, G. Fischer, and W. Heinrich, "A 8W GaNBased H-Bridge Class-D PA for the $900 \mathrm{MHz}$ Band Enabling Ternary Coding," IEEE International Microwave Symposium Digest, pp. 1-3, June 2012.

[17] H. Nakamizo, K. Mukai, S. Shinjo, H. Gheidi, and P. Asbeck, "Over 65\% PAE GaN Voltage-Mode Class-D Power Amplifier for $465 \mathrm{MHz}$ Operation Using Bootstrap Drive," IEEE Radio Wireless Week Digiest, 2015, pp. 1-4, Jan. 2015

[18] Y. Hong, K. Mukai, H. Gheidi, S. Shinjo, and P. Asbek, "High Efficiency GaN Switching Converter IC with Bootstrap Driver for Envelope Tracking Applications," IEEE MTT-S RFIC Digiest, pp. 353356, June 2013.

[19] A. Wentzel, S. Chevtchenko, P. Kurpas, and W. Heinrich, "A Flexible GaN MMIC Enabling Digial Power Amplifiers for the Future Wireless Infrastructure," IEEE MTT-S International Microwave Symposium Digitest, pp. 1-4, May 2015.

[20] M. P. van der Heijden, and M. Acar, "A Radio-Frequency Reconfigurable CMOS-GaN Class-E Chireix Power Amplifier," IEEE MTT-S International Microwave Symposium Digest, pp. 1-4, June 2014.

[21] S. Heck, A. Brackle, M. Schmidt, and F. Schuller, et al."A SiGe Hbridge Switching Amplifier for Class-S Amplfiers with Clock Frequencies up to $6 \mathrm{GHz}$, "IEEE German Microwave Conference Digiest, pp. 174-177, March 2010.

[22] K. Blau, and E. Serebryakova, "The Appropriate Design of the Reconstruction Filter and Its Influence on the Output Power and Efficiency of Class-S and Quasi Class-S Power Amplifiers," IEEE Microwave, Radar, and Wireless Communication (MIKON) Digest, June 2014.

[23] D. Green, Arlington, and C. L. Dohrman, et al. "Heterogeneous Integration for Revolutionary Microwave Circuit at DARPA," Microave Journal, vol. 58, no. 6, pp. 22-38, June 2015. 